\title{
Psychological Impact of Cancellation of Elective Surgeries for Ophthalmic Patients During COVID- 19 Pandemic
}

Stephanie Chu ( $\square$ chustephanie.k@gmail.com )

United Christian Hospital https://orcid.org/0000-0003-2000-0182

David To

United Christian Hospital

Candice Liu

United Christian Hospital

Tony Wong

United Christian Hospital

Kenneth Li

United Christian Hospital

Research Article

Keywords: COVID-19, Cataract, Psychosocial impact, cataract surgeries

Posted Date: March 10th, 2021

DOI: https://doi.org/10.21203/rs.3.rs-267441/v1

License: (a) (i) This work is licensed under a Creative Commons Attribution 4.0 International License. Read Full License 


\section{Abstract}

Purpose

To identify the psychological impact of canceling cataract operations on patients during COVID-19 pandemic.

Methods

99 participants aged from 59 years old who had their cataract surgeries postponed or as scheduled, were studied using the standardized patient health questionnaire (PHQ-9) and generalized anxiety disorder questionnaire (GAD-7) from April to June 2020 at Kowloon East Cataract Center, Tseung Kwan O Hospital, Hong Kong.

\section{Results}

None of the patients who had the cataract surgeries rescheduled reached the cutoff score for major depression in PHQ-9, whereas for GAD-7, 5 patients had mild symptoms of anxiety, 1 had severe symptoms $(p$-value $=0.76)$.

\section{Conclusion}

There was no significant psychosocial impact of cancellation of cataract surgeries on patients.

\section{Introduction}

Cataract is one of the leading causes of visual impairment [1]. Visual impairment is reported to have a greater negative impact on the quality of life in elderly than other age-related conditions such as increased depression, social isolation and increased mortality [2]. As a result of the emergence of coronavirus disease 2019 (COVID-19), the substantial impact of coronavirus COVID-19 has disrupted hospital services. Cataract surgeries were suspended and postponed as medical resources had to be reserved for the urgent procedures amid the COVID-19. As the pandemic continues to evolve, patients may respond to higher levels of depression and anxiety.

Although there are studies that look at psychological stress in frontline medical healthcare workers [3], the psychological burden on patients has not been studied. Depression affects about $5 \%$ of men and up to $10 \%$ of women in developed countries, whereas up to $33 \%$ of people might have anxiety disorder at some time of their life [4-7]. The increasing prevalence of these mood disorders is largely attributed to environmental factors, particularly stress. As COVID-19 has strongly influenced both the psychological and physical health of the general population, this study aims to identify the psychological impact of cancelling cataract operations on patients during this pandemic.

\section{Methodology}


99 patients who were scheduled to have cataract operations at Kowloon East Cataract Center, Tseung Kwan 0 Hospital, Hong Kong from April to June 2020 were recruited for the study.

Patients were divided into two groups. The treatment group included patients with their surgeries postponed while the patients in the control group underwent the surgeries as scheduled.

This research was approved by the Research Ethics Committee (Kowloon Central/Kowloon East). The questionnaire study was clearly explained to all participants and informed consent was obtained prior to the study.

\section{Data collection}

Written informed consent was obtained, and a survey comprising twenty-one questions was given for each patient. The survey included patients' demographics, knowledge and practices towards COVID-19. Patient health questionnaire (PHQ-9) and generalized anxiety disorder questionnaire (GAD-9) were used as a composite measure of depression and anxiety.

\section{Statistical analysis}

Inter-rater reliability of surveyors was used as there was more than one surveyor. The point prevalence was calculated. The prevalence was calculated by gender, age group and preoperative visual acuity for subgroup analysis. Confidence interval for prevalence was calculated using R software. To study the association between depression, anxiety status and a set of possible explanatory variables, regression analysis and chi square test were used. Odds ratios with confidence intervals were calculated in $\mathrm{R}$ software. A p-value less than $5 \%$ was considered to be statistically significant.

\section{Results}

Patient demographics, knowledge and practices towards COVID-19, PHQ-9 and GAD-9 results are displayed in Table $1-4$ respectively.

During the COVID-19 outbreak, a significant number of elective cataract surgeries were postponed due to service cutdown. Out of 99 patients, 74 of them had their surgeries postponed, 34 of them were postponed by themselves while 40 of them were postponed by the cataract center. Out of the 34 patients, most of them were worried about COVID-19 while a minority could not attend due to compulsory quarantine from travelling abroad.

The PHQ-9 total score for the nine items ranges from $0-27$. Using the mental health professional (MHP) reinterview as the criterion standard, $\mathrm{PHQ}-9$ score $\geq 10$ was used as a cut off for major depression [8]. For GAD-7, a score of 0-4 was considered to be minimal, 5-9 to be mild, 10-14 to be moderate and 15-21 to be severe [9]. Although patients who postponed the surgeries were mostly due to concern about 
contracting COVID-19, none of the patients who had the cataract surgeries rescheduled reached the cutoff score for major depression in PHQ-9, whereas for GAD-7, 5 patients had mild symptoms, 1 had severe symptoms of anxiety.

There was no statistically significant difference in comparing the symptoms of anxiety among patients with and without cataract surgeries postponed ( $p$-value $=0.76$ ). Depression symptoms could not be compared as no patients reached above the cutoff score. Subgroup analysis was performed and showed no differences in anxiety and depression symptoms in terms of gender, age ( $\geq 70$ and $<70$ years old), preoperative visual acuity $(\geq 0.1$ and $<0.1)$.

\section{Discussion}

The majority of the patients (> $80 \%$ ) did not experience any symptoms of depression and anxiety. None of the patients reached the cut off for major depression and of those who reported anxiety symptoms, the severity was minimal. The effect of cancellation of cataract surgeries on their psychosocial health was insignificant. As such, the questionnaire results indicated that this sample was relatively not distressed. In addition, since the postponement was due to a well understood reason, i.e. COVID-19 pandemic, and likely well within their expectations, the change in anxiety or depressive symptoms was not apparent in these patients.

On the other hand, moderate frequency handwashing six to ten times a day was associated with a lower risk of coronavirus infection [10]. $65 \%$ of the patients had higher levels of hand hygiene (>10 times per day). Given that COVID-19 appeared to have a similar transmission mechanism to seasonal coronavirus [11-12], the patients demonstrated adequate personal hygiene. Links between higher levels of anxiety and high frequency hand washers were not observed.

This study has potential limitations. As the questionnaires were conducted after the cataract operations, this could contribute to the relief of anxiety or depressive symptoms. Furthermore, the patients recruited in this study were mostly elderly. Older adults might experience fewer life events and thus less stressful than younger age groups [13-14].

In conclusion, there was no significant psychosocial impact of cancellation of cataract surgeries on patients. As the expanding outbreak of COVID-19 will lead to further cancellation of elective surgeries, the long-term impact on the patients' psychosocial wellbeing is yet to be studied.

\section{Declarations}

\section{Funding Info and competing interests}

The authors received no financial support for the research, authorship and publication of this article. There are no competing interests. 


\section{Consent to participate and publish}

This research was approved by the Research Ethics Committee (Kowloon Central/Kowloon East).

The questionnaire study was clearly explained to all participants and informed consent was obtained prior to the study.

\section{Authors Contribution}

All authors have contributed equally to the work.

\section{Data Availability}

The authors ensure full access to all the data in the study and take responsibility for the reliability of the data and the precision of the data analysis.

\section{Animal Research}

There is no animal research involved in this study.

\section{References}

1. Bourne RRA, Flaxman SR, Braithwaite T, et al. Magnitude, temporal trends, and projections of the global prevalence of blindness and distance and near vision impairment: a systematic review and meta-analysis. Lancet Glob Health. 2017;5(9):e888-e897. doi:10.1016/S2214-109X(17)30293-0

2. Brown RL, Barrett AE. Visual impairment and quality of life among older adults: an examination of explanations for the relationship. J Gerontol B Psychol Sci Soc Sci. 2011;66(3):364-373. doi:10.1093/geronb/gbr015

3. Xiang YT, Yang Y, Li W, et al. Timely mental health care for the 2019 novel coronavirus outbreak is urgently needed. Lancet Psychiatry. 2020;7(3):228-229. doi:10.1016/S2215-0366(20)30046-8

4. Kessler RC, McGonagle KA, Swartz M, Blazer DG, Nelson CB. Sex and depression in the National Comorbidity Survey. I: Lifetime prevalence, chronicity and recurrence. J Affect Disord. 1993;29(23):85-96. doi:10.1016/0165-0327(93)90026-g

5. Weissman MM, Bland R, Joyce PR, Newman S, Wells JE, Wittchen HU. Sex differences in rates of depression: cross-national perspectives. J Affect Disord. 1993;29(2-3):77-84. doi:10.1016/01650327(93)90025-f

6. Kroenke K, Spitzer RL, Williams JB. The PHQ-9: validity of a brief depression severity measure. J Gen Intern Med. 2001 Sep;16(9):606-13. doi: 10.1046/j.1525-1497.2001.016009606.x. PMID: 11556941; PMCID: PMC1495268.

7. Kessler RC, Petukhova M, Sampson NA, Zaslavsky AM, Wittchen $\mathrm{H}-U$. Twelve-month and lifetime prevalence and lifetime morbid risk of anxiety and mood disorders in the United States. Int J Methods Psychiatr Res. 2012;21(3):169-184. doi:10.1002/mpr.1359 
8. Aldwin CM, Sutton KJ, Chiara G, Spiro A 3rd. Age differences in stress, coping, and appraisal: findings from the Normative Aging Study. J Gerontol B Psychol Sci Soc Sci. 1996;51(4):P179-P188. doi:10.1093/geronb/51b.4.p179

9. Spitzer RL, Kroenke K, Williams JB, Löwe B. A brief measure for assessing generalized anxiety disorder: the GAD-7. Arch Intern Med. 2006;166(10):1092-1097. doi:10.1001/archinte.166.10.1092

10. Beale, S., Johnson, A., Zambon, M., Hayward, A. and Fragaszy, E., 2020. Hand Hygiene Practices and the Risk of Human Coronavirus Infections in a UK Community Cohort. Wellcome Open Research, 5, p.98.

11. Lai CC, Shih TP, Ko WC, Tang HJ, Hsueh PR. Severe acute respiratory syndrome coronavirus 2 (SARSCoV-2) and coronavirus disease-2019 (COVID-19): The epidemic and the challenges. Int $J$ Antimicrob Agents. 2020;55(3):105924. doi:10.1016/j.ijantimicag.2020.105924

12. Kutter JS, Spronken MI, Fraaij PL, Fouchier RA, Herfst S. Transmission routes of respiratory viruses among humans. Curr Opin Virol. 2018;28:142-151. doi:10.1016/j.coviro.2018.01.001

13. Cohen, L., 1988. Life Events And Psychological Functioning. Newbury Park: Sage Publications, pp.96-122.

14. Meeks S, Carstensen LL, Tamsky BF, Wright TL, Pellegrini D. Age differences in coping: does less mean worse. Int J Aging Hum Dev. 1989;28(2):127-140. doi:10.2190/UXKQ-4J3X-TEHT-7NU2

\section{Tables}

Table 1

Patient demographics

\begin{tabular}{|ll|}
\hline Questionnaire response & 99 \\
\hline Number of Male & 56 \\
Number of Female & 43 \\
\hline Age range & $55-89$ years old \\
\hline Cataract operation cancelled/postponed due to COVID-19 outbreak & $74(74.7 \%)$ \\
\hline Cause of postponement & \\
Self postponed & $54(54.7 \%)$ \\
Postponed by cataract center & $45(45.3 \%)$ \\
\hline
\end{tabular}


Table 2

Knowledge and practices toward COVID-19

Which of the following is/are the route(s) of transmission of COVID-19?

Eyes

$63(63.6 \%)$

Respiratory tract

$12(12.1 \%)$

Gastrointestinal tract

$35(35.3 \%)$

All of the above

How often do you wash your hands each day?

0-3 times

$3(3 \%)$

4-6 times

$15(15.21 \%)$

7-9 times

$16(16.2 \%)$

10 times or more

$65(65.7 \%)$

How often do you rub your eyes?

Never

$47(47.5 \%)$

Occasional

Always

$49(49.5 \%)$

$3(3 \%)$ 
Table 3

PHQ-9 questionnaire

How often have you been bothered by the following over the past two weeks?

Little interest or pleasure in doing things?

Not at all

Several days

$(83.8 \%)$

More than half the days

13

Nearly every day

Feeling down, depressed, or hopeless?

Not at all

Several days

More than half the days

Nearly every day

Trouble falling or staying asleep, or sleeping too much?

Not at all

Several days

More than half the days

Nearly every day

Feeling tired or having little energy?

Not at all

Several days

More than half the days

Nearly every day

Poor appetite or overeating?

Not at all

Several days

More than half the days

Nearly every day

Feeling bad about yourself - or that you are a failure or have let yourself or your family down?

Not at all

Several days

More than half the days

Nearly every day 
How often have you been bothered by the following over the past two weeks?

Trouble concentrating on things, such as reading the newspaper or watching television?

Not at all

Several days

More than half the days

Nearly every day

Moving or speaking so slowly that other people could have noticed? Or so fidgety or restless that you have been moving a lot more than usual?

Not at all

Several days

More than half the days

Nearly every day

Thoughts that you would be better off dead, or thoughts of hurting yourself in some way?

Not at all

More than half the days

Nearly every day 
Table 4

GAD-7 questionnaire

\begin{tabular}{|c|c|}
\hline \multicolumn{2}{|c|}{$\begin{array}{l}\text { How often have you been bothered by the following over the past } \\
\text { two weeks? }\end{array}$} \\
\hline $\begin{array}{l}\text { Feeling nervous, anxious, or on edge? } \\
\text { Not at all } \\
\text { Several days } \\
\text { More than half the days } \\
\text { Nearly every day }\end{array}$ & $\begin{array}{l}78(76.8 \%) \\
19(19.2 \%) \\
3(3 \%) \\
1(1 \%)\end{array}$ \\
\hline $\begin{array}{l}\text { Not being able to stop or control worrying? } \\
\text { Not at all } \\
\text { Several days } \\
\text { More than half the days } \\
\text { Nearly every day }\end{array}$ & $\begin{array}{l}89(89.9 \%) \\
6(6.1 \%) \\
3(3 \%) \\
1(1 \%)\end{array}$ \\
\hline $\begin{array}{l}\text { Worrying too much about different things? } \\
\text { Not at all } \\
\text { Several days } \\
\text { More than half the days } \\
\text { Nearly every day }\end{array}$ & $\begin{array}{l}90(90.9 \%) \\
6(6.1 \%) \\
2(2 \%) \\
1(1 \%\end{array}$ \\
\hline $\begin{array}{l}\text { Trouble relaxing? } \\
\text { Not at all } \\
\text { Several days } \\
\text { More than half the days } \\
\text { Nearly every day }\end{array}$ & $\begin{array}{l}88(88.9 \%) \\
9(9.1 \%) \\
1(1 \%) \\
1(1 \%)\end{array}$ \\
\hline $\begin{array}{l}\text { Being so restless that it's hard to sit still? } \\
\text { Not at all } \\
\text { Several days } \\
\text { More than half the days } \\
\text { Nearly every day }\end{array}$ & $\begin{array}{l}91(91.9 \%) \\
6(6.1 \%) \\
1(1 \%) \\
1(1 \%)\end{array}$ \\
\hline $\begin{array}{l}\text { Becoming easily annoyed or irritable? } \\
\text { Not at all } \\
\text { Several days } \\
\text { More than half the days } \\
\text { Nearly every day }\end{array}$ & $\begin{array}{l}88(88.9 \%) \\
9(9.1 \%) \\
1(1 \%) \\
1(1 \%)\end{array}$ \\
\hline $\begin{array}{l}\text { Feeling afraid as if something awful might happen? } \\
\text { Not at all } \\
\text { Several days } \\
\text { More than half the days } \\
\text { Nearly every day }\end{array}$ & $\begin{array}{l}86(86.9 \%) \\
11(11.1 \%) \\
1(1 \%) \\
1(1 \%)\end{array}$ \\
\hline
\end{tabular}

